\title{
Right ventricle-to-pulmonary artery conduit for surgical management of transposition of great arteries with a complex coronary pattern
}

\author{
T. K. Susheel Kumar, MD, ${ }^{a}$ Mario Briceno-Medina, MD, ${ }^{\mathrm{b}}$ Abdul H. Khan, MD, ${ }^{\mathrm{b}}$ and
}

Christopher J. Knott-Craig, MD, ${ }^{a}$ Memphis, Tenn

\footnotetext{
From the Departments of apediatric Cardiothoracic Surgery and 'Pediatric Cardiology, Le Bonheur Children's Hospital and University of Tennessee Health Science Center, Memphis, Tenn.

Disclosures: Authors have nothing to disclose with regard to commercial support.

Received for publication April 1, 2017; revisions received May 2, 2017; accepted for publication May 16, 2017; available ahead of print June 22, 2017.

Address for reprints: T. K. Susheel Kumar, MD, Department of Pediatric Cardiothoracic Surgery, Le Bonheur Children's Hospital, University of Tennessee Health Science Center, Memphis, TN 38103 (E-mail: tskumar@uthsc.edu).

J Thorac Cardiovasc Surg 2017; 154:e69-71

$0022-5223 / \$ 36.00$

Copyright (c) 2017 by The American Association for Thoracic Surgery

http://dx.doi.org/10.1016/j.jtcvs.2017.05.049
}

Video clip is available online.

The arterial switch operation (ASO) has emerged as the standard procedure for surgical correction of transposition of the great arteries (TGA). ${ }^{1,2}$ The success of the ASO hinges on the safe translocation of the coronary arteries, and the results are closely linked to the patient's coronary pattern. ${ }^{1,2}$ Complex variations in coronary pattern rarely preclude a safe translocation. ${ }^{1,3}$ Innovative techniques have been described to deal with such complex variations. ${ }^{3-7}$ We describe a modification of the ASO in a neonate with TGA and a complex coronary pattern.

\section{CASE DESCRIPTION}

A newborn infant underwent an ASO for a diagnosis of TGA, an intact ventricular septum, and a "usual" coronary pattern. During the operation, both coronary ostia were found located in the right sinus close to each other ("kissing ostia") and the facing commissure. The left main coronary artery (LMCA) exhibited a short intramural course before it exited the aorta and bifurcated into anterior descending and circumflex branches, whereas the right coronary artery (RCA) emerged from the right ostium and immediately gave rise to a large acute marginal branch.

Following takedown of the posterior commissure, both coronary ostia were excised en bloc in a single button,

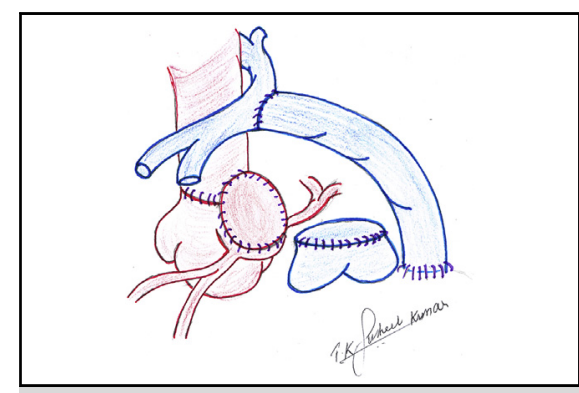

The aortocoronary flap technique and right ventricleto-pulmonary artery conduit.

Central Message

The risk of coronary compression associated with the single aortocoronary flap technique during the arterial switch operation can be obviated by placement of a right ventricle-topulmonary artery conduit.

See Editorial Commentary page e73.

including the entire intramural segment of the LMCA (Video 1). Given the close proximity of the coronary ostia, the short intramural course of the LMCA, and

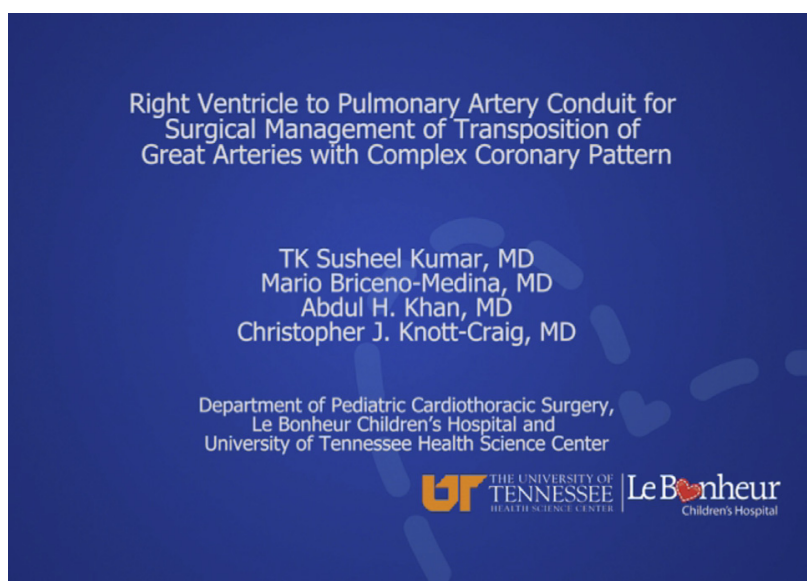

VIDEO 1. Explanation of the relevance of our case report and description of the surgical technique. Video available at: http://www.jtcvsonline.org/ article/S0022-5223(17)31094-2/addons. 


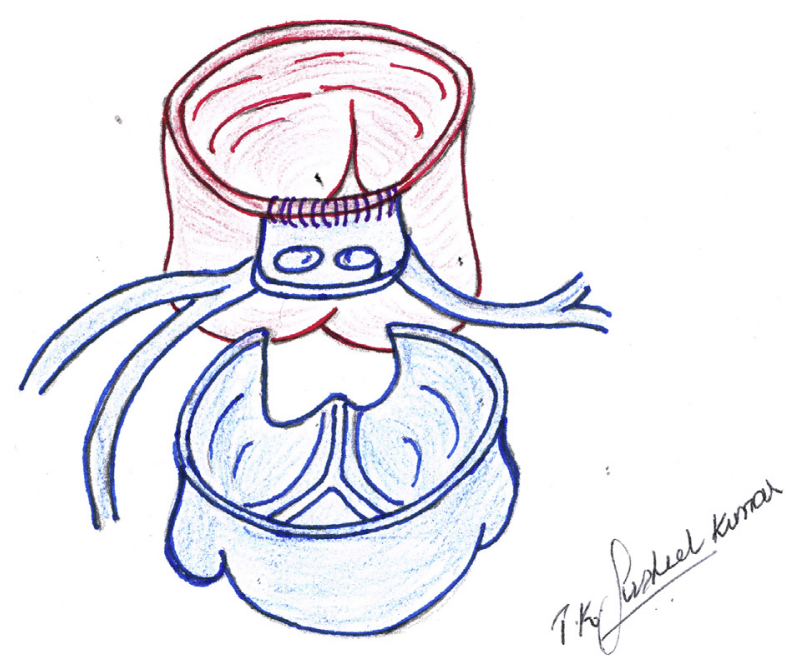

FIGURE 1. Technique for coronary artery harvest as a single button.

the resultant inadequate margins for sewing, we elected to not divide the button. The button was sutured to the edge of the transected pulmonary artery, and a patch of autologous pericardium was used to create an anterior pouch (Figures 1 and 2).

An initial attempt to separate the patient from cardiopulmonary bypass (CPB) failed because of deterioration in myocardial perfusion during the terminal stages of weaning. A second attempt following augmentation of

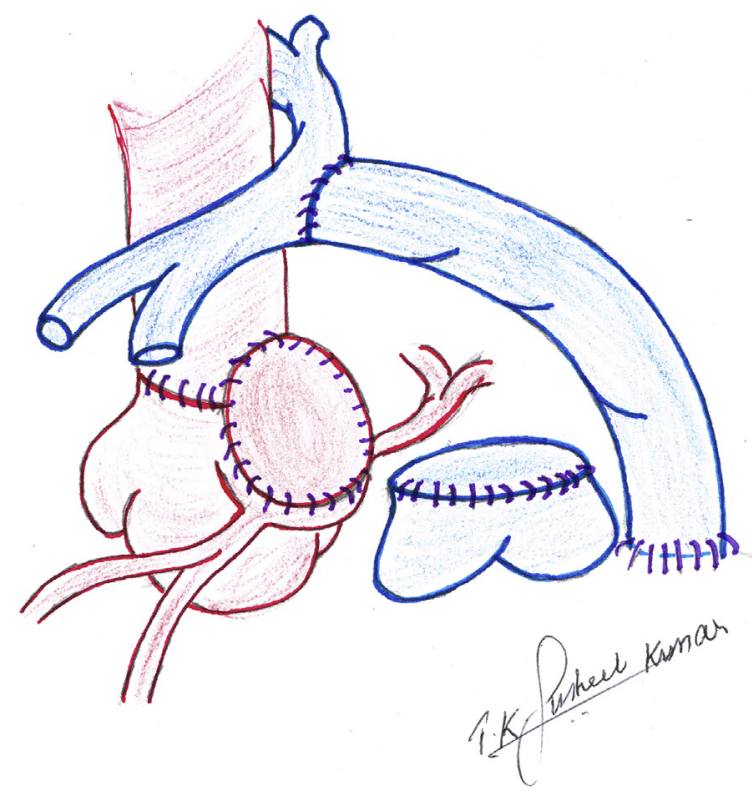

FIGURE 2. The aortocoronary flap technique and a right ventricle-topulmonary conduit. A standard Lecompte maneuver was performed to bring the pulmonary bifurcation anterior to the ascending aorta. the posterior wall of the neopulmonary artery to relieve any tension on the coronary pouch also failed. It was obvious that the poor myocardial perfusion was a result of compression of the coronary button from the neopulmonary artery.

At this point, we decided to divide the main pulmonary artery, oversew the pulmonary valve, and close it with a patch of extracellular matrix (CorMatrix Cardiovascular, Atlanta, Ga). An incision was made over the infundibulum of the right ventricle, and a $10-\mathrm{mm}$ aortic homograft was placed between the right ventricle and the right pulmonary artery to shift the right ventricular outflow tract anteriorly and rightward away from the coronary button. The patient was then separated from CPB without difficulty and with minimal inotropic support. He had an uneventful recovery. $\mathrm{He}$ subsequently underwent replacement of the right ventricle-to-pulmonary artery conduit at age 2 years and remained well at the time of this report. A preoperative angiogram demonstrated widely patent coronary arteries.

\section{DISCUSSION}

Current management of TGA is centered around the ASO in the early neonatal period following medical stabilization. Coronary artery anomalies and difficulty transferring the coronary artery remain the single most important risk factors for early mortality following the ASO. ${ }^{1,2,8}$ In addition, coronary artery obstruction is present in $5 \%$ to $7 \%$ of survivors and remains the most common cause of morbidity and mortality following the ASO. ${ }^{2}$ An intramural coronary artery occurs in approximately $5 \%$ of cases of TGA. ${ }^{7,8}$ Asou and colleagues ${ }^{7}$ have advocated excision of the coronary arteries as a single disc following detachment of the commissure and division into 2 separate buttons for implantation; however, division of a single ostium might not always be possible, especially if the ostia are too close or the intramural course is too short. ${ }^{6,8}$ In addition, there could be other situations where the coronary artery pattern may be too complex for transfer. ${ }^{3}$ Alternatives, including the Damus operation and atrial switch, have been proposed in such situations. Innovative techniques, including creation of an aortopulmonary window and bovine pericardial baffle without actual coronary translocation, have been described as well. In a series of 46 patients with TGA and an intramural course of coronary arteries, 5 of the 9 patients who were managed with a single aortocoronary flap technique sustained a major coronary event, including death from coronary 
button compression. ${ }^{7}$ Our technique of adding a right ventricle-to-pulmonary artery conduit eliminates this risk of coronary compression.

We believe that the single aortocoronary flap technique is indeed a useful technique for treating patients with certain difficult coronary patterns. This technique's poor reputation stems from a failure to recognize and address the potential coronary compression. The addition of a right ventricle-to-pulmonary artery conduit obviates this risk of coronary compression and any concerns of a neopulmonary valve. Our technique differs from that described by Damus and colleagues, ${ }^{9}$ who also used a right ventricle-topulmonary artery conduit.

\section{References}

1. Pasquali SK, Hasselblad V, Li JS, Kong DF, Sanders SP. Coronary artery pattern and outcome of arterial switch operation for transposition of the great arteries: a meta-analysis. Circulation. 2002;106:2575-80.
2. Villafane J, Lantin-Hermoso MR, Bhatt AB, Tweddell JS, Geva T, Nathan M, et al D-transposition of the great arteries: the current era of the arterial switch operation. J Am Coll Cardiol. 2014;64:498-511.

3. Moat NE, Pawade A, Lamb RK. Complex coronary arterial anatomy in transposition of the great arteries: arterial switch procedure without coronary relocation. J Thorac Cardiovasc Surg. 1992;103:872-6.

4. Aubert J, Pannetier A, Couvelly JP, Unal D, Rouault F, Delarue A. Transposition of the great arteries: new technique for anatomical correction. Br Heart J. 1978;40: 204-8

5. Takeuchi S, Katogi T. New technique for the arterial switch operation in difficult situations. Ann Thorac Surg. 1990;50:1000.

6. Koshiyama H, Nagashima M, Matsumura G, Hiramatsu T, Nakanishi T, Yamazaki K. Arterial switch operation with and without coronary relocation for intramural coronary arteries. Ann Thorac Surg. 2016;102 1353-9.

7. Asou T, Karl TR, Pawade A, Mee RB. Arterial switch: translocation of the intramural coronary artery. Ann Thorac Surg. 1994;57:461-5.

8. Metton O, Calvaruso D, Gaudin R, Mussa S, Raisky O, Bonnet D, et al Intramural coronary arteries and outcome of neonatal arterial switch operation. Eur J Cardiothorac Surg. 2010;37:1246-53.

9. Damus PS, Thomson NB Jr, McLoughlin TG. Arterial repair without coronary relocation for complete transposition of the great vessels with ventricular septal defect: report of a case. J Thorac Cardiovasc Surg. 1982; $83: 316-8$. 